\title{
Intranasal dexmedetomidine combined with local anesthesia for conscious sedation during breast lumpectomy: A prospective randomized trial
}

\author{
YA-JING YUAN $^{1}$, PENG ZHOU ${ }^{1}$, FEI XIA ${ }^{1}$, XIAO-BEI ZHANG ${ }^{1}$, SHAN-SHAN HE $^{2}$, \\ DONG-YONG GUO ${ }^{1}$, YU-HONG XING ${ }^{1}$ and HONG-WEI ZHAO ${ }^{1}$
}

\begin{abstract}
Departments of ${ }^{1}$ Anesthesia and ${ }^{2}$ Breast Reconstruction, Tianjin Medical University Cancer Institute \& Hospital, Key Laboratory of Cancer Prevention and Therapy, National Clinical Research Centre for Cancer, Tianjin Clinical Research Center for Cancer, Tianjin 300060, P.R. China
\end{abstract}

Received February 27, 2020; Accepted June 22, 2020

DOI: $10.3892 / \mathrm{ol} .2020 .11938$

\begin{abstract}
Breast lumpectomy is usually performed under general or local anesthesia. To the best of our knowledge, whether conscious sedation with intranasal dexmedetomidine and local anesthesia is an effective anesthetic technique has not been studied. Thus, the present study aimed to investigate the effectiveness of conscious sedation with intranasal dexmedetomidine combined with local anesthesia in breast lumpectomy, and to identify its optimal dose. A prospective randomized, double-blinded, placebo-controlled, single-center study was designed, and patients undergoing breast lumpectomies were recruited based on the inclusion and exclusion criteria. All patients were randomly allocated to four groups: i) Local anesthesia with $0.9 \%$ intranasal saline (placebo); local anesthesia with ii) $1 \mu \mathrm{g} \cdot \mathrm{kg}^{-1}$; iii) $1.5 \mu \mathrm{g} \cdot \mathrm{kg}^{-1}$; or iv) $2 \mu \mathrm{g} \cdot \mathrm{kg}^{-1}$ intranasal dexmedetomidine. The sedation status, pain relief, vital signs, adverse events, and satisfaction of patient and surgeon were recorded. Patients in the three dexmedetomidine groups were significantly more sedated and experienced less pain compared with the placebo group $45 \mathrm{~min}$ after intranasal dexmedetomidine administration and during $30 \mathrm{~min}$ in the
\end{abstract}

Correspondence to: Dr Hong-Wei Zhao, Department of Anesthesia, Tianjin Medical University Cancer Institute \& Hospital, Key Laboratory of Cancer Prevention and Therapy, National Clinical Research Centre For Cancer, Tianjin Clinical Research Center for Cancer, 24 Bishuixidao Street, Tianjin 300060, P.R. China

E-mail: zhaohongwei1105@163.com

Abbreviations: PACU, post-anesthesia care unit; CONSORT, Consolidated Standards of Reporting Trials; OAA/S, Observer's Assessment of Alertness/Sedation; ASA, American Society of Anesthesiologists; BIS, bispectral index; NRS, numerical rating scale; SBP, systolic blood pressure; HR, heart rate; $\mathrm{SpO}_{2}$, oxygen saturation; RR, respiratory rate; ANOVA, analysis of variance

Key words: conscious sedation, lumpectomy, dexmedetomidine, intranasal administration, sedation post-anesthesia care unit. Patients in the $1.5 \mu \mathrm{g} . \mathrm{kg}^{-1}$ group were more sedated compared with the $1 \mu \mathrm{g} \cdot \mathrm{kg}^{-1}$ group (without reaching statistical significance), whereas the $1.5 \mu \mathrm{g} . \mathrm{kg}^{-1}$ group exhibited a similar level of sedation $45 \mathrm{~min}$ after intranasal dexmedetomidine administration compared with the $2 \mu \mathrm{g} \cdot \mathrm{kg}^{-1}$ group. In addition, patients in the 1 and $1.5 \mu \mathrm{g} . \mathrm{kg}^{-1}$ group experienced no adverse hemodynamic effects. Patient and surgeon satisfaction were greater in the $1.5 \mu \mathrm{g} . \mathrm{kg}^{-1}$ group compared with the 1 and $2 \mu \mathrm{g} . \mathrm{kg}^{-1}$ groups. Taken together, the results of the present study suggested that conscious sedation with intranasal dexmedetomidine and local anesthesia may be an effective anesthetic for breast lumpectomy surgery, and that the optimal dose for intranasal dexmedetomidine administration may be $1.5 \mu \mathrm{g} \cdot \mathrm{kg}^{-1}$, as it resulted in good sedation and patient satisfaction without adverse effects.

\section{Introduction}

Breast cancer is currently the most common cancer among Chinese women $(1,2)$. For a number of women with breast cancer, breast lumpectomy with intraoperative pathological assessment is the preferred treatment to make an intraoperative decision (3). Breast cancer surgery performed under general anesthesia is associated with a potential risk of complications, which may make the patient feel unpleasant and delay patient recovery after surgery (4,5). Minor breast surgery requires fast and effective local anesthetic techniques with minimal side effects to allow the patient to recover quickly $(6,7)$. Local anesthesia alone can make patients feel uncomfortable and distressed during surgery $(8,9)$. Thus, the application of conscious sedation techniques may reduce the need for local anesthesia.

Dexmedetomidine is a highly selective $\alpha_{2}$-adrenoreceptor agonist that induces sedation providing improved hemodynamic stability without eliciting respiratory depression (10-13). Previous studies have reported that dexmedetomidine is rapidly and efficiently absorbed after intranasal administration, and is better tolerated compared with intravenous administration (14-17). Additionally, intranasal dexmedetomidine has been successfully used for conscious sedation 
under local anesthesia in numerous minor surgeries, including neurotologic procedures and dental surgery (18-20). In addition, intranasal administration of dexmedetomidine has been investigated in studies involving children, which demonstrated that intranasal administration may be a feasible alternative in patients requiring light sedation $(21,22)$; however, more attention should be paid to the differences in dexmedetomidine dosage between children and adults (15-17,20-22). A number of studies have reported the application of intravenous dexmedetomidine in breast lumpectomy (23-25). Based on the similar efficacy between intravenous and intranasal administration, the present study hypothesized that intranasal dexmedetomidine may be effective in breast lumpectomy procedures. In order to evaluate the efficacy and identify the optimal dose of intranasal dexmedetomidine for conscious sedation, and to make patients more comfortable and cooperative during surgery, the modified Observer's Assessment of Alertness/Sedation (OAA/S) score (22), bispectral index (BIS) and pain were monitored. Additionally, systolic blood pressure (SBP), heart rate (HR), oxygen saturation $\left(\mathrm{SpO}_{2}\right)$ and respiratory rate $(\mathrm{RR})$ were monitored to evaluate the side effects during breast lumpectomy under local anesthesia. The optimal dexmedetomidine dose that yielded the best sedation and the least adverse effects was also investigated.

\section{Materials and methods}

Study design. The present prospective randomized, double-blinded, placebo-controlled, single-center study was approved by the Ethics Committee of Tianjin Medical University Cancer Institute \& Hospital (approval no. bc201512; Tianjin, China), and was registered at ClinicalTrials.gov (trial registration no. NCT02675049). Participants were enrolled during February and March 2016 from Tianjin Medical University Cancer Institute \& Hospital, and written informed consent was obtained. All procedures were performed in accordance with the ethical standards of the responsible committee on human experimentation (institutional and national) and with the Helsinki Declaration of 1975, as revised in 2000.

Inclusion criteria. Patients included in the present study were women aged between 20 and 60 years. Patients with ASA (American Society of Anesthesiologists) physical status I and II (26) who were scheduled for breast lumpectomy at the Tianjin Medical University Cancer Institute and Hospital were enrolled in the study. A total of 100 patients were recruited.

Exclusion criteria. The exclusion criteria were a history of heart block, upper respiratory tract infection, asthma, allergy to dexmedetomidine or local anesthetics, memory or cognitive dysfunction, pregnancy, lack of understanding of the consent process, impaired liver or renal function, hypertension, concurrent application of $\beta$-receptor blockers, and a history of drug or alcohol abuse. Baseline demographic (age and body weight) and clinical ASA status characteristics were recorded.

Intervention. The patients were instructed to fast at least $6 \mathrm{~h}$ prior to surgery. No premedication was administered and patients were sent to the induction room $1 \mathrm{~h}$ prior to surgery.
The patients were monitored routinely for electrocardiography, $\mathrm{SpO}_{2}$, non-invasive blood pressure and BIS. Prior to dexmedetomidine administration, the operative, sedation and pain assessment procedures were explained. The patients were assigned randomly before surgery on the basis of a computer-generated random number table (complete randomization) at a 1:1:1:1 allocation ratio to receive $1,1.5$ or $2 \mu \mathrm{g} . \mathrm{kg}^{-1}$ dexmedetomidine or $0.9 \%$ saline (placebo) intranasally $45 \mathrm{~min}$ before surgery. Both the patients and the investigators were blinded to the randomized intervention. An independent investigator and an anesthesiologist who were unaware of patient allocation prepared and administered the drug or placebo. A parenteral preparation of $100 \mu \mathrm{g} \cdot \mathrm{ml}^{-1}$ dexmedetomidine (Ai Bei Ning; Jiangsu Heng-rui Medicine Co., Ltd.) was used without further dilution. An equivalent volume of the placebo $(0.9 \%$ saline) or undiluted dexmedetomidine was administered evenly by bilateral nasal dripping while the patients were in a recumbent position $\sim 45 \mathrm{~min}$ prior to surgery. All surgical procedures were performed by the same surgical team comprising of three surgeons. Local anesthetic was administered by local infiltration with $1 \%$ lidocaine $\sim 5 \mathrm{~min}$ before surgery and the volume was recorded. Inadequate analgesia was managed by local anesthetic infiltration into the surgical site.

Measurements and outcomes. The primary outcome was OAA/S, which was measured after drug administration, during surgery and during recovery in the post-anesthesia care unit (PACU). A score of 4 or 5 was considered the optimal OAA/S score in our study group. The secondary outcomes were BIS, pain [scored using a numerical rating scale (NRS)] (27), vital signs ( $\mathrm{SBP}, \mathrm{HR}, \mathrm{SpO}_{2}$ and $\mathrm{RR}$ ), adverse effects and satisfaction with sedation. Adverse effects included hypotension (defined as SBP $<90 \mathrm{mmHg}$ ), bradycardia (defined as HR $<50 \mathrm{bpm}$ ), oxygen desaturation (defined as $\mathrm{SpO}_{2}<92 \%$ ), respiratory depression (defined as a ventilatory frequency $<10 / \mathrm{min}$ ), nausea and vomiting. The surgical condition, graded by the surgeon and patient, has been described in a previous study (28).

Baseline data were recorded before the commencement of surgery. The observation indices were measured 15, 30 and 45 min after drug administration, at which point resection commenced. The measurements were then taken every $5 \mathrm{~min}$ during surgery, and every $10 \mathrm{~min}$ after surgery in the PACU.

Sample size. The sample size was calculated according to the previous study by Yuen et al (29). The mean modified OAA/S scores for the 1 and $1.5 \mu \mathrm{g} . \mathrm{kg}^{-1}$ dexmedetomidine groups in the present study were 5.2 and 4.6, respectively, and the standard deviation (SD) was 0.5 , which led to a standardized difference of 1.2 SDs between the 1 and $1.5 \mu \mathrm{g} \cdot \mathrm{kg}^{-1}$ groups. Based on this result, the present study needed to have $\sim 90 \%$ power to detect a 1.2-SD difference between any two of the three dexmedetomidine groups using two-sided Student's t-tests conducted using a Bonferroni-adjusted $\mathrm{P}<0.0167$ significance level. Calculations using PASS2011 software (version 11.0.10; NCSS, LLC) demonstrated that 20 subjects per group provide the two-sided Student's t-test with $89.6 \%$ power at a $\mathrm{P}<0.0167$ significance level, thereby satisfying power requirements. To maintain $\sim 90 \%$ power in the event of a 
$20 \%$ dropout rate, the sample size was increased to 25 subjects per group for a total of 100 study subjects.

Statistical analysis. All statistical analyses were performed using SPSS software version 18.0 (SPSS Inc). Continuous variables following a normal distribution were expressed as mean \pm SD and analyzed using Student's t-test. Categorical variables and continuous variables following an abnormal distribution were expressed as median and interquartile range, and were assessed using Mann-Whitney $U$ test. To detect differences between the groups in terms of primary and secondary outcomes, a two-step procedure was employed. First, the placebo and $1 \mu \mathrm{g} \cdot \mathrm{kg}^{-1}$ dexmedetomidine groups were compared in terms of OAA/S, BIS, NRS, SBP, HR, RR or frequency of 'good' surgical conditions. If the difference was not statistically significant $(\mathrm{P}>0.05)$, no further analysis was performed. However, if $\mathrm{P}<0.05$, the three dexmedetomidine groups were compared with each other. $\mathrm{P}<0.0167$ (Bonferroni-adjusted P-value) was considered to indicate a statistically significant difference.

\section{Results}

Baseline characteristics. A total of 100 hundred patients were separated into four groups, with each group consisting of 25 patients. The mean (SD) age of the patients was 37.5 (11.5), 41.1 (10.6), 41.9 (7.0) and 42.3 (11.1) years, and the mean weight was $62.5(11.5), 59.7(8.7), 58.5(7.3)$ and $60.2(12.7) \mathrm{kg}$ in the placebo group and $1,1.5$, and $2 \mu \mathrm{g} . \mathrm{kg}^{-1}$ dexmedetomidine groups, respectively (Table I). No significant difference in demographic data and clinical features was observed among the groups (Table I). All patients met the eligibility criteria and completed the study (Fig. 1). The mean (SD) time between dexmedetomidine administration and the start of surgery was 47.4 (10.8), 52.4 (24.3), 47.2 (20.0) and 43.7 (13.6) $\mathrm{min}$ in the placebo group and $1,1.5$, and $2 \mu \mathrm{g} \cdot \mathrm{kg}^{-1}$ dexmedetomidine groups, respectively ( $\mathrm{P}=0.397$; data not shown).

Outcomes. The modified OAA/S scores of the four groups at different time intervals before and after administration of the drug were investigated (Fig. 2). The modified OAA/S scores were significantly lower in the $1 \mu \mathrm{g} . \mathrm{kg}^{-1}$ group compared with the placebo group $45 \mathrm{~min}$ after intranasal $(\mathrm{U}=204.0 ; \mathrm{P}=0.0003)$ and after $30 \mathrm{~min}$ in the PACU $(\mathrm{U}=516.5$; $\mathrm{P}<0.001)$. The $2 \mu \mathrm{g} . \mathrm{kg}^{-1}$ group exhibited greater sedation compared with the $1.5 \mu \mathrm{g} . \mathrm{kg}^{-1}$ group but these differences did not have any statistical significance $(\mathrm{U}=68.0 ; \mathrm{P}=0.300)$ at $45 \mathrm{~min}$ after intranasal administration; also, no significant difference was observed in the level of sedation between the 1.5 and $1 \mu \mathrm{g} . \mathrm{kg}^{-1}$ groups $(\mathrm{U}=59.5 ; \mathrm{P}=0.026)$ at $45 \mathrm{~min}$ after intranasal administration.

The BIS scores between the placebo group and other groups were compared using Mann-Whitney U test. Compared with that of the placebo group, the $1 \mu \mathrm{g} \cdot \mathrm{kg}^{-1}$ group had significantly lower BIS scores at $30 \mathrm{~min}$ after intranasal administration $(\mathrm{BIS}=91$; $\mathrm{U}=383.0 ; \mathrm{P}<0.001)$ and after $30 \mathrm{~min}$ in the PACU (BIS=84; $\mathrm{U}=327.0 ; \mathrm{P}=0.002$; Fig. 3). Additionally, the BIS scores of the $1 \mu \mathrm{g} . \mathrm{kg}^{-1}$ group were significantly greater compared with those of the 1.5 and $2 \mu \mathrm{g} . \mathrm{kg}^{-1}$ groups $30 \mathrm{~min}$ after resection (U=34.5; $\mathrm{P}=0.004$; and $\mathrm{U}=36.5 ; \mathrm{P}=0.002$, respectively); however, there was no significant difference at $30 \mathrm{~min}$ in the PACU (U=203.5;
$\mathrm{P}=0.596$; and $\mathrm{U}=208.5 ; \mathrm{P}=0.684$, respectively). In addition, no significant difference was observed between the BIS scores of the 1.5 and $2 \mu \mathrm{g} \cdot \mathrm{kg}^{-1}$ groups.

The median pain NRS scores at each sample time were collected and presented in Fig. 4. The patients in the placebo group had a significantly higher pain score compared with patients in the $1 \mu \mathrm{g} . \mathrm{kg}^{-1}$ group $10 \mathrm{~min}$ into surgery (U=436.5; $\mathrm{P}=0.015)$ and after $30 \mathrm{~min}$ in the PACU $(\mathrm{U}=405.0 ; \mathrm{P}=0.012$; Fig. 4). The NRS scores in the $1 \mu \mathrm{g} . \mathrm{kg}^{-1}$ group were comparable to those in the 1.5 and $2 \mu \mathrm{g} . \mathrm{kg}^{-1}$ groups $10 \mathrm{~min}$ into surgery ( $\mathrm{U}=262.5 ; \mathrm{P}=0.318$; and $\mathrm{U}=254.0 ; \mathrm{P}=0.245$, respectively) and after $30 \mathrm{~min}$ in the PACU $(\mathrm{U}=194.5 ; \mathrm{P}=0.079$; and $\mathrm{U}=223.0$; $\mathrm{P}=0.037$, respectively; Fig. 4). In addition, no significant differences were observed in the volume of local anesthetic administered between the four groups ( $\mathrm{P}=0.280$, Table I).

The three dexmedetomidine groups exhibited significant decreases in mean value of SBP during surgery and recovery compared with the baseline values (Fig. 5A). In addition, compared with the placebo group, the SBP of the $1 \mu \mathrm{g} \cdot \mathrm{kg}^{-1}$ group was significantly lower 45 min after intranasal dexmedetomidine administration $(\mathrm{P}=0.001)$. Additionally, all three dexmedetomidine groups exhibited significantly lower HR $45 \mathrm{~min}$ after drug administration and after $30 \mathrm{~min}$ in the PACU compared with the control group (Fig. 5B). In addition, compared with the placebo group, the $1 \mu \mathrm{g} \cdot \mathrm{kg}^{-1}$ group had similar HR reduction during surgery and recovery (Fig. 5B).

Dexmedetomidine administration had no significant effect on $\mathrm{SpO}_{2}$ levels or $\mathrm{RR}$ compared with the baseline values $(\mathrm{P}>0.05)$ and no significant differences were observed in the $\mathrm{SpO}_{2}$ and RR between the four groups (data not shown). In addition, the intranasal administration was well tolerated by all patients; none of them developed local irritation or pain due to the administration, or complained of any unpleasant smell or taste associated with intranasal drug or placebo administration.

Safety outcomes. Only the $2 \mu \mathrm{g} \cdot \mathrm{kg}^{-1}$ group developed bradycardia (4\% of total patients) and significant hypotension (1\% of total patients) after dexmedetomidine administration. Most patients were asymptomatic and remained untreated. Only one patient with bradycardia required treatment with $0.5 \mathrm{mg}$ atropine. The other two dexmedetomidine groups did not develop bradycardia or hypotension. No significant differences were observed in the incidence of nausea and vomiting between the four groups $(\mathrm{P}=0.286$; data not shown).

Patient satisfaction. In the dexmedetomidine groups, the patients expressed more comfortable experiences during surgery, which were indicative of satisfactory sedation $(\mathrm{P}=0.157)$. The surgeons graded the surgical conditions as 'good' (indicating adequate sedation) more frequently in the dexmedetomidine groups compared with the placebo group (72\%; $\mathrm{P}=0.066$ ), but no significant differences were observed between the dexmedetomidine groups $(\mathrm{P}=0.768$, Table I).

\section{Discussion}

The present study evaluated the efficacy and dose of combined intranasal dexmedetomidine and local anesthesia for conscious sedation during breast lumpectomy. Patients who received 
Table I. Baseline demographic and clinical characteristics and intraoperative aspects.

\begin{tabular}{|c|c|c|c|c|}
\hline Characteristics & $\begin{array}{c}\text { Placebo } \\
(n=25)\end{array}$ & $\begin{array}{c}1 \mu \mathrm{g} \cdot \mathrm{kg}^{-1} \\
\text { dexmedetomidine } \\
(\mathrm{n}=25)\end{array}$ & $\begin{array}{c}1.5 \mu \mathrm{g} \cdot \mathrm{kg}^{-1} \\
\text { dexmedetomidine } \\
\quad(\mathrm{n}=25)\end{array}$ & $\begin{array}{c}2 \mu \mathrm{g} \cdot \mathrm{kg}^{-1} \\
\text { dexmedetomidine } \\
(\mathrm{n}=25)\end{array}$ \\
\hline Age, years & $37.5 \pm 11.5$ & $41.1 \pm 10.6$ & $41.9 \pm 7.0$ & $42.3 \pm 11.1$ \\
\hline Body weight, kg & $62.5 \pm 11.5$ & $59.7 \pm 8.7$ & $58.5 \pm 7.3$ & $60.2 \pm 12.7$ \\
\hline \multicolumn{5}{|l|}{ ASA } \\
\hline I & 10 & 12 & 13 & 14 \\
\hline II & 15 & 13 & 12 & 11 \\
\hline Preoperative BIS & $97.1 \pm 2.1$ & $92.3 \pm 18.1$ & $96.4 \pm 2.6$ & $96.4 \pm 1.8$ \\
\hline Preoperative OAA/S & 6.0 & 6.0 & 6.0 & 6.0 \\
\hline Preoperative NRS & 0 & 0 & 0 & 0 \\
\hline Duration from DEX to surgery, min & $47.4 \pm 11.8$ & $52.4 \pm 24.3$ & $47.1 \pm 20.0$ & $43.7 \pm 13.6$ \\
\hline Duration of surgery, min & $25.6 \pm 9.6$ & $24.3 \pm 8.9$ & $28.6 \pm 13.0$ & $30.3 \pm 16.4$ \\
\hline Total volume-local anesthetic used, ml & $31.3 \pm 15.1$ & $27.7 \pm 15.6$ & $29.6 \pm 19.4$ & $29.3 \pm 18.7$ \\
\hline Surgical conditions graded 'good'a & $18(72.0 \%)$ & $23(92.0 \%)$ & $25(100.0 \%)$ & $24(96.0 \%)$ \\
\hline
\end{tabular}

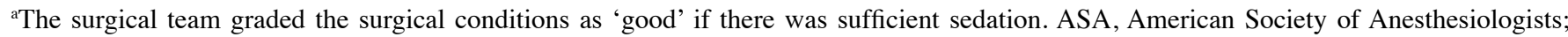
BIS, bispectral index; DEX, dexmedetomidine; NRS, numerical rating scale of pain; OAAS/S, modified Observer's Assessment of Alertness/Sedation Scale; Preop, preoperative.

\section{CONSORT 2010 flow diagram}

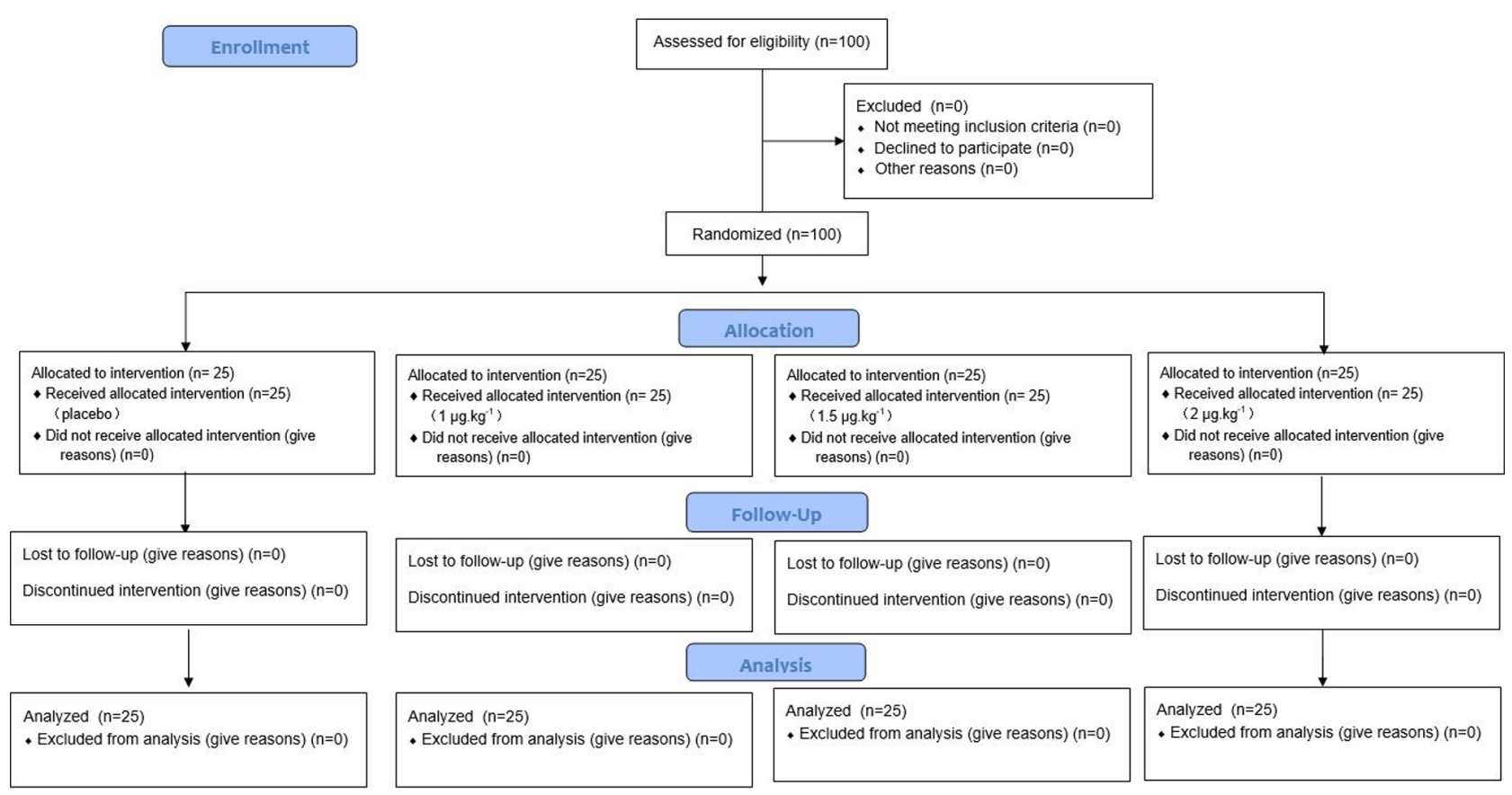

Figure 1. Flow diagram showing the disposition of the study subjects throughout the phases of the study. Placebo consisted of intranasal $0.9 \%$ saline. The remaining three groups received the indicated doses of dexmedetomidine. CONSORT, Consolidated Standards of Reporting Trials.

dexmedetomidine were significantly more sedated, experienced less pain, and were more satisfied with the sedation compared with patients in the placebo group. In addition, the results of the present study suggested that $1.5 \mu \mathrm{g} \cdot \mathrm{kg}^{-1}$ was the optimal dose of intranasal dexmedetomidine, which yielded satisfactory sedation with good surgical condition, patient sedation satisfaction, and no serious adverse events.
One of the main causes of postoperative complications is general anesthesia, which is frequently used for sedation, and causes nausea and vomiting in $50 \%$ of cases (7). Local anesthesia may be an alternative to general anesthesia for this type of surgery (5). Dexmedetomidine is an effective drug for conscious sedation in patients who undergo minor surgery $(14,17,30,31)$. A previous study demonstrated that 


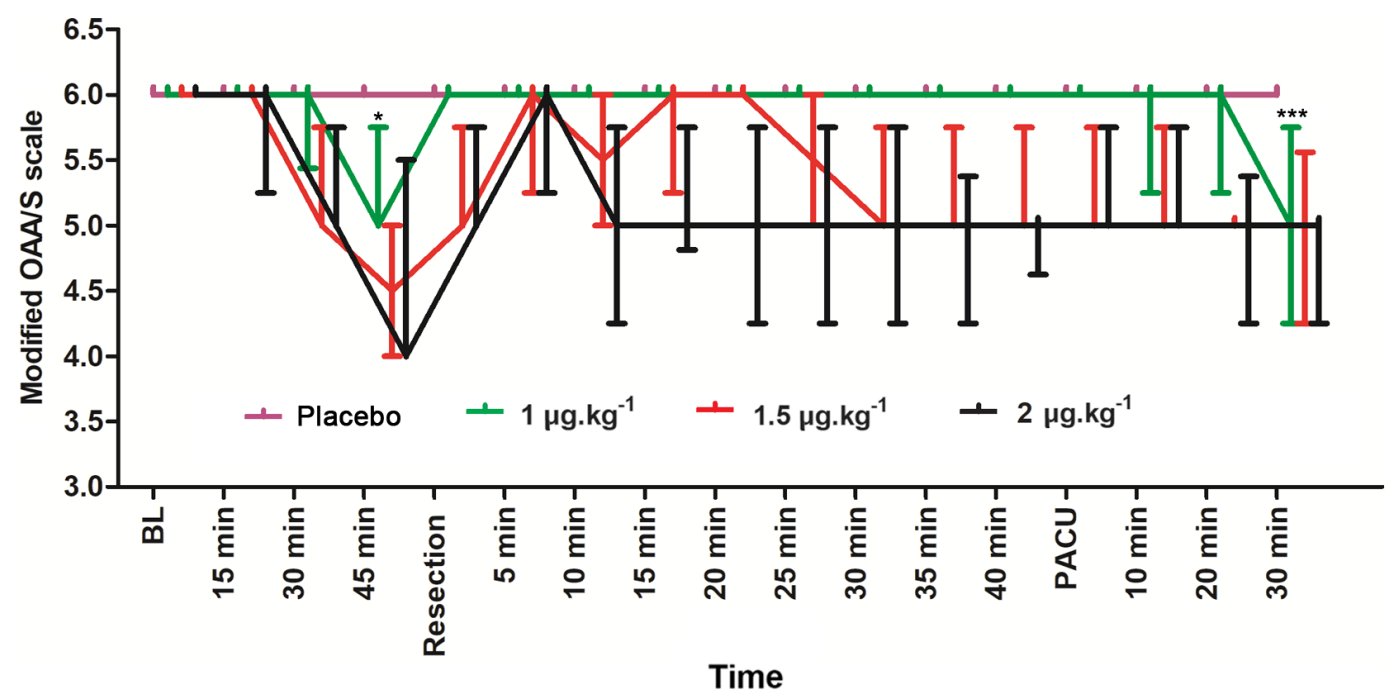

Figure 2. Changes over time in the modified OAA/S score of patients. Modified OAA/S was measured at BL, in the induction room, during the intraoperative

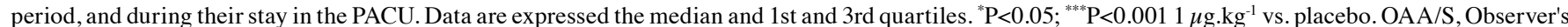
Assessment of Alertness/Sedation; PACU, post-anesthesia care unit; BL, baseline.

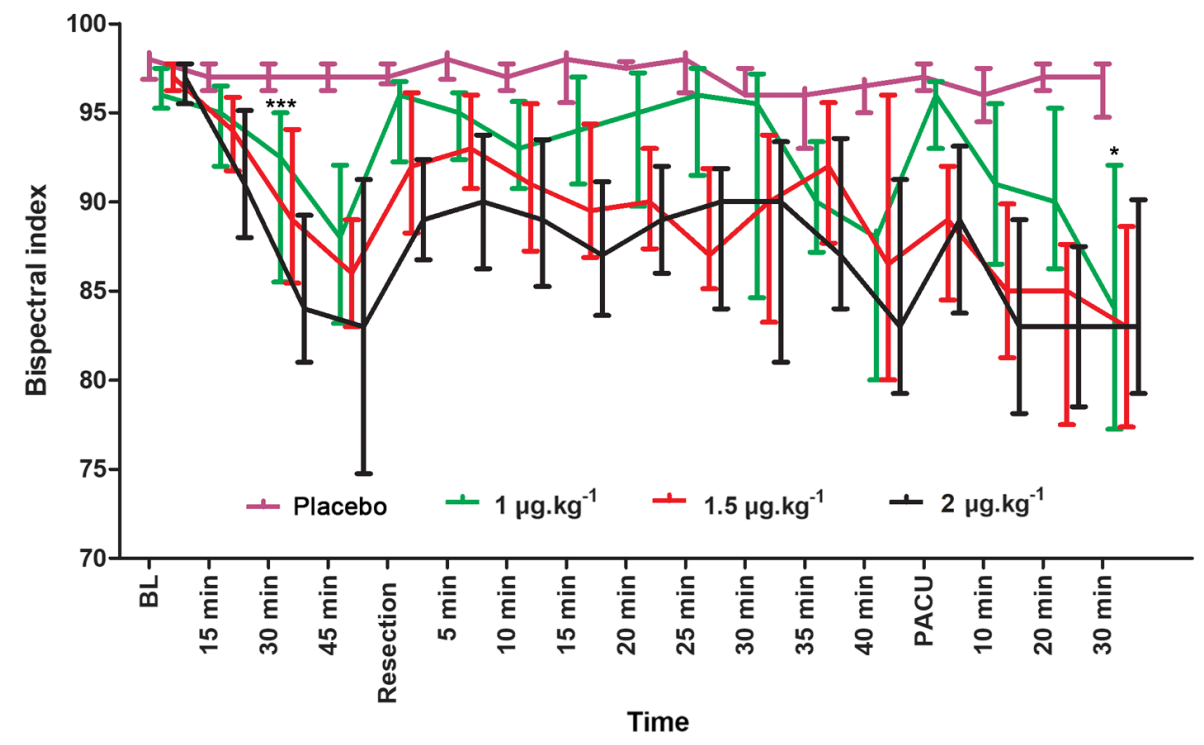

Figure 3. Changes over time in the bispectral index values of patients at BL, in the induction room, during the intraoperative period, and during their stay in the PACU. The data points were shifted slightly horizontally to avoid overlapping. Data are expressed the median and 1 st and 3 rd quartiles. ${ }^{*} \mathrm{P}<0.05 ;{ }^{* * * *} \mathrm{P}<0.001$ $1 \mu \mathrm{g} \cdot \mathrm{kg}^{-1}$ vs. placebo. BL, baseline; PACU, post-anesthesia care unit.

intranasal dexmedetomidine was noninvasive and more tolerable compared with intravenous administration (14). In addition, the intranasal route is safe, effective, comfortable and convenient (14,22,32-34). Iirola et al (28) demonstrated that administration of intranasal dexmedetomidine had a high bioavailability of $65 \%(35-93 \%)$ and could potentially have useful sedative effects in surgical procedures. To the best of our knowledge, to date there is no study that has reported the efficacy of intranasal dexmedetomidine for conscious sedation during breast lumpectomy under local anesthesia. The present study demonstrated that patients who received intranasal dexmedetomidine exhibited improved clinical sedation and analgesia compared with patients in the placebo group. In addition, the surgeons considered that the surgical conditions in the dexmedetomidine groups were superior compared with those in the placebo group. It was also demonstrated that intranasal dexmedetomidine could provide good clinical analgesia and sedation for a long duration of time of up to at least $70 \mathrm{~min}$ after surgery had started.

To identify the optimal intranasal dose providing the best sedation while inducing minimal side effects, three different intranasal doses were tested in the present study. These doses $\left(1,1.5\right.$ and $\left.2 \mu \mathrm{g} . \mathrm{kg}^{-1}\right)$ were chosen on the basis of previous studies $(29,31,35)$. However, only a few studies have assessed intranasal dexmedetomidine in adults $(14,16,17)$. Because of the different requirements of anesthesia and surgery between children and adults, and as the selected doses were based on previous studies in adults, the dose of dexmedetomidine for sedation may 


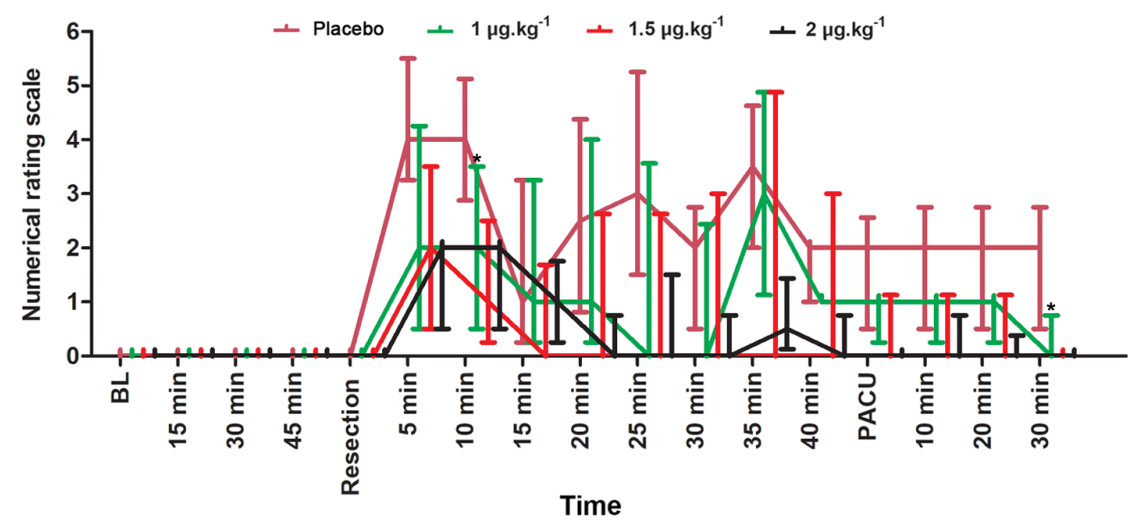

Figure 4. Changes in the numerical rating scale pain scores of patients at BL, in the induction room, during the intraoperative period and during their stay in the PACU. Data are expressed the median and 1st and 3rd quartiles. ${ }^{*} \mathrm{P}<0.051 \mu \mathrm{g} \cdot \mathrm{kg}^{-1} \mathrm{vs}$. placebo. BL, baseline; PACU, post-anesthesia care unit.

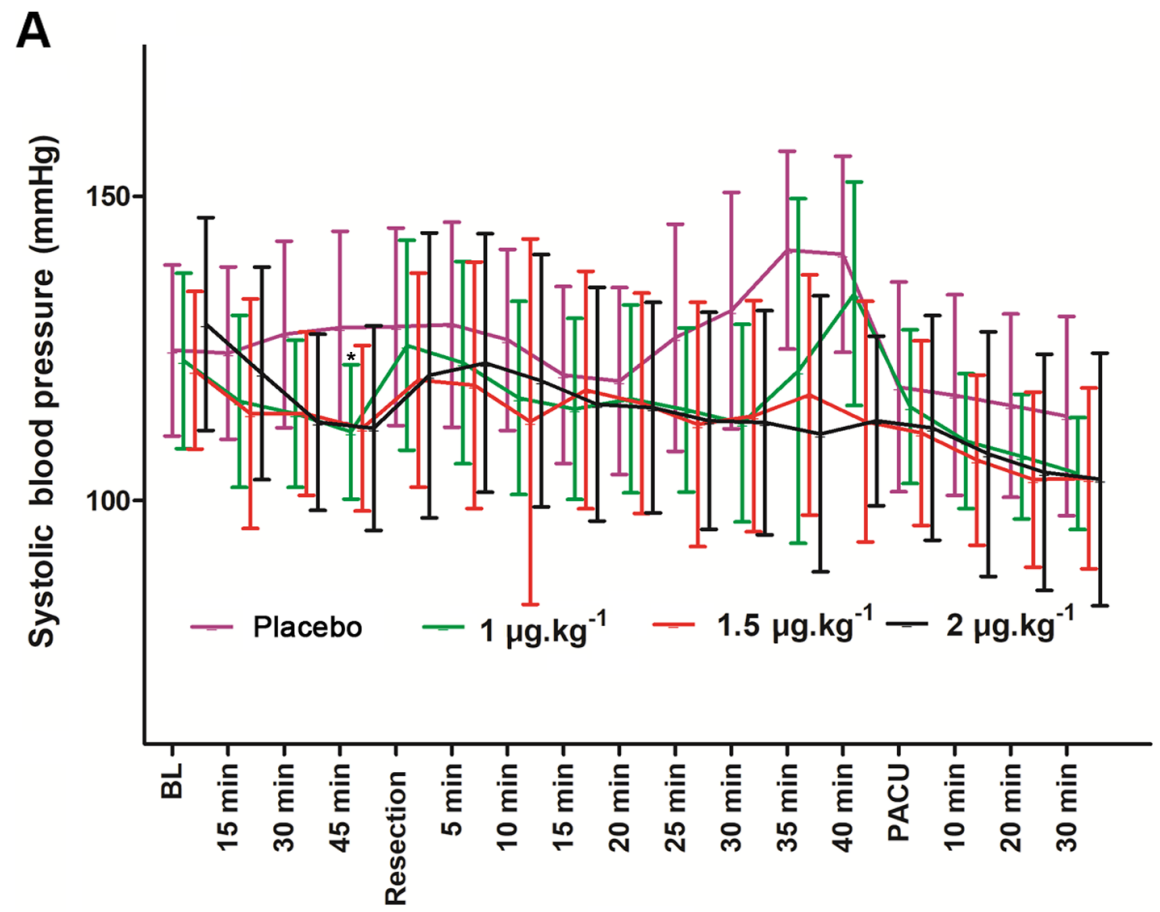

B

\section{Time}

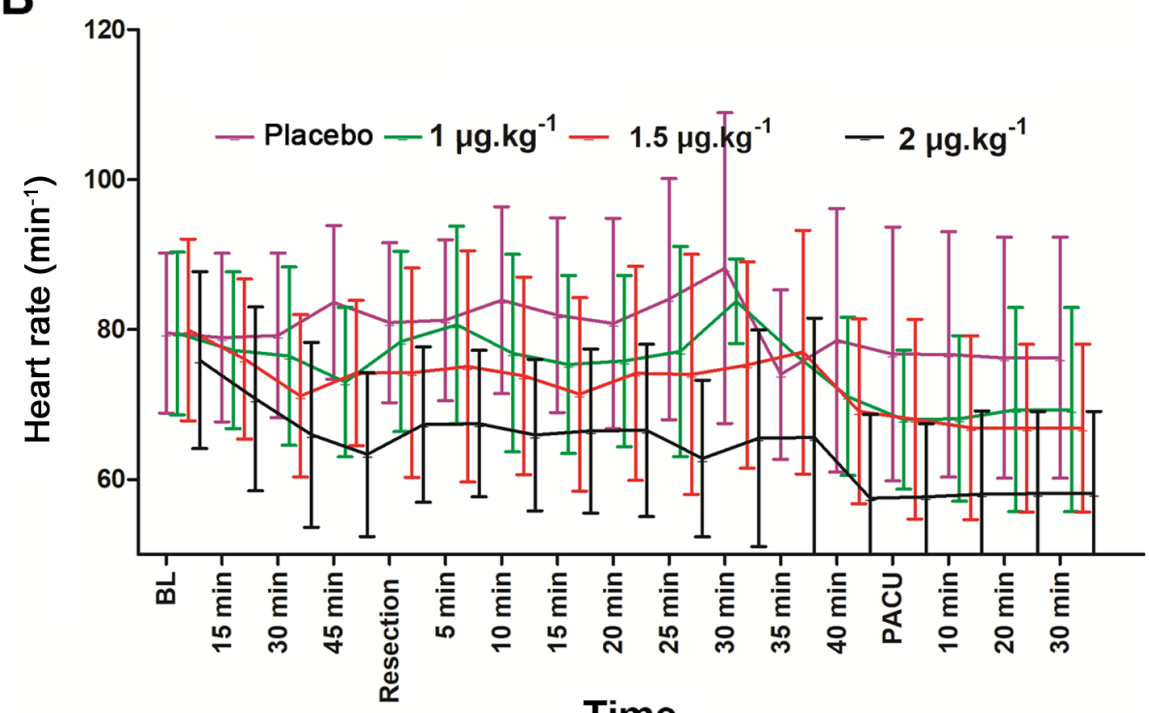

Time

Figure 5. Changes in (A) systolic blood pressure and (B) heart rate of patients at BL, in the induction room, during the intraoperative period and during their stay in the PACU. ${ }^{*} \mathrm{P}<0.051 \mu \mathrm{g} . \mathrm{kg}^{-1}$ vs. placebo. Data are expressed as mean \pm SD. BL, baseline; PACU, post-anesthesia care unit. 
be different $(15-17,20-22,31,32)$. The results of the present study demonstrated that there was a dose-dependent increase in sedation levels when dexmedetomidine was given intranasally, which was consistent with the findings of previous studies $(25,36)$. In the current study, the level of sedation was significantly greater in the dexmedetomidine groups compared with that in the placebo group. Notably, Yuen et al (29) also demonstrated that 1 and $1.5 \mu \mathrm{g} \cdot \mathrm{kg}^{-1}$ intranasal dexmedetomidine produced clinically significant sedation in healthy volunteers. In addition, patients receiving $1 \mu \mathrm{g} \cdot \mathrm{kg}^{-1}$ intranasal dexmedetomidine for unilateral third molar surgery with local anesthesia were more sedated perioperatively with greater postoperative pain relief compared with intranasal water (17). Additionally, Zhang et al (37) reported that $1 \mu \mathrm{g} \cdot \mathrm{kg}^{-1}$ intranasal dexmedetomidine appeared to be safe and efficacious for patients undergoing elective electrochemotherapy for facial vascular malformations. The present study demonstrated that the $1.5 \mu \mathrm{g} \cdot \mathrm{kg}^{-1}$ group achieved greater sedation compared with the $1 \mu \mathrm{g} . \mathrm{kg}^{-1}$ group, although it did not reach a statistically significant difference. In addition, the $2 \mu \mathrm{g} . \mathrm{kg}^{-1}$ group also did not achieve a significant difference compared with the $1.5 \mu \mathrm{g} . \mathrm{kg}^{-1}$ group. However, $1.5 \mu \mathrm{g} \cdot \mathrm{kg}^{-1}$ may be the optimal dose even if there were no significant differences.

The NRS pain scores also indicated that the dexmedetomidine groups experienced greater analgesia compared with the placebo group, as they felt less pain and were more tolerant. Mohta et al (38) reported that paravertebral block using intravenous dexmedetomidine in patients undergoing breast cancer surgery provided greater analgesia. Dexmedetomidine administration has been reported to result in significant bradycardia and hypotension (39). When dexmedetomidine was administered in adults before stimulation or intervention (i.e., surgery), it attenuated the hemodynamic response to stimulation and reduced arterial blood pressure and HR (40). The present study observed that, regardless of dose, dexmedetomidine significantly decreased SBP during surgery and recovery compared with that of the placebo group, but this hemodynamic change did not cause patient discomfort. There was also a significant drop in HR compared with the baseline values at the same time point in the dexmedetomidine groups. Although the $1 \mu \mathrm{g} \cdot \mathrm{kg}^{-1}$ group had a similar HR to the placebo group during surgery and recovery, the two higher dose groups had a lower HR during surgery and/or recovery. These changes may account for the relatively high rates of profound hypotension and bradycardia in the $2 \mu \mathrm{g} \cdot \mathrm{kg}^{-1}$ group. Notably, the most frequently reported adverse events associated with dexmedetomidine treatment are hypotension and bradycardia (41). Although patients in the $2 \mu \mathrm{g} . \mathrm{kg}^{-1}$ group achieved a relatively greater level of sedation and analgesia, the cardiovascular side effects rendered this dose suboptimal. Since the optimal dose should yield sufficient sedation and analgesia without such adverse effects, the results of the present study suggested that the optimal dose of dexmedetomidine for intranasal administration may be $1.5 \mu \mathrm{g} \cdot \mathrm{kg}^{-1}$. Notably, patients who received $1.5 \mu \mathrm{g} \cdot \mathrm{kg}^{-1}$ dexmedetomidine remained aware during surgery and tolerated the procedure well, which allowed patients to cooperate with the surgeon to perform various required behaviors.
The present study had some limitations. First, the postoperative pain relief was not monitored after $30 \mathrm{~min}$ in the PACU. Whether intranasal dexmedetomidine can enhance postoperative pain relief under local anesthesia in breast lumpectomy requires further investigation. Second, intranasal dexmedetomidine was administered by dripping the solution into both nostrils with a $1 \mathrm{ml}$ syringe. An optimal delivery system may have more consistent results. One such system would be the mucosal atomization device nasal spray that was used in a previous study to deliver intranasal dexmedetomidine during third molar extraction (16). Third, although the results of the present study together with previous study (42) indicated the efficacy and safety of intranasal dexmedetomidine administration during breast lumpectomy, future studies need to be conducted to focus on the safety in a larger sample size. Fourth, individual differences in drug tolerance may also provide bias since the time point for surgery was $45 \mathrm{~min}$ after intranasal dexmedetomidine was selected according to previous studies $(14,28-29)$ instead of plasma concentration.

In conclusion, patients undergoing breast lumpectomy surgery who received intranasal $1.5 \mu \mathrm{g} \cdot \mathrm{kg}^{-1}$ dexmedetomidine attained significant and satisfactory sedation without experiencing any adverse effects compared with patients who received 1 and $2 \mu \mathrm{g} \cdot \mathrm{kg}^{-1}$ intranasal dexmedetomidine. Future studies should be conducted to focus on the efficacy and safety in a larger sample size.

\section{Acknowledgements}

The authors would like to thank Professor Jing-Bo Zhai (Institute of Traditional Chinese Medicine, Tianjin University of Traditional Chinese Medicine) for their assistance with the statistical analysis.

\section{Funding}

This study was supported by the National Natural Science Foundation of China (grant no. 81501140).

\section{Availability of data and materials}

The datasets used and/or analyzed during the current study are available from the corresponding author on reasonable request.

\section{Authors' contributions}

HWZ and YJY conceptualized the study and analyzed data. YJY, PZ, FX, XBZ, SSH, DYG and YHX acquired and analyzed the data. YJY, PZ, FX, XBZ, SSH, DYG, YHX and HWZ wrote the manuscript. HWZ and YJY revised the manuscript from a critical perspective for important intellectual content. All authors read and approved the final manuscript.

\section{Ethics approval and consent to participate}

This study was approved by the Ethics Committee of Tianjin Medical University Cancer Institute \& Hospital (approval no. bc201512) and was registered at ClinicalTrials.gov 
(registration no. NCT02675049). Written informed consent to participate was obtained from the patients.

\section{Patient consent for publication}

Not applicable.

\section{Competing interests}

The authors declare that they have no competing interests.

\section{References}

1. Hong W and Dong E: The past, present and future of breast cancer research in China. Cancer Lett 35: 1-5, 2014.

2. Li H, Zheng RS, Zhang SW, Zeng HM, Sun KX, Xia CF, Yang ZX, Chen WQ and He J: Incidence and mortality of female breast cancer in China, 2014. Zhonghua Zhong Liu Za Zhi 40: 166-171, 2018 (In Chinese).

3. Tevis SE, Neuman HB, Mittendorf EA, Kuerer HM, Bedrosian I, DeSnyder SM, Thompson AM, Black DM, Scoggins ME, Sahin AA, et al: Multidisciplinary intraoperative assessment of breast specimens reduces number of positive margins. Ann Surg Oncol 25: 2932-2938, 2018.

4. Sessler DI, Pei L, Huang Y, Fleischmann E, Marhofer P, Kurz A Mayers DB, Meyer-Treschan TA, Grady M, Tan EY, et al: Recurrence of breast cancer after regional or general anaesthesia: A randomised controlled trial. Lancet 394: 1807-1815, 2019.

5. Pusch F, Freitag H, Weinstabl C, Obwegeser R, Huber E and Wildling E: Single-injection paravertebral block compared to general anaesthesia in breast surgery. Acta Anaesthesiol Scand 43: 770-774, 1999.

6. Manfè AZ, Marchesini M, Bortolato A, Feltracco P and Lumachi F: Ropivacaine versus levobupivacaine for minor breast surgery in outpatients: Inversion of postoperative pain relief efficacy. In Vivo 26: 1075-1077, 2012.

7. Calì Cassi L, Biffoli F, Francesconi D, Petrella G and Buonomo O: Anesthesia and analgesia in breast surgery: The benefits of peripheral nerve block. Eur Rev Med Pharmacol Sci 21: 1341-1345, 2017.

8. FitzGerald S, Odor PM, Barron A and Pawa A: Breast surgery and regional anaesthesia. Best Pract Res Clin Anaesthesiol 33: 95-110, 2019

9. Burgess C, Cornelius V, Love S, Graham J, Richards M and Ramirez A: Depression and anxiety in women with early breast cancer: Five year observational cohort study. BMJ 330: 702, 2005.

10. Sezen G, Demiraran Y, Seker IS, Karagoz I, Iskender A, Ankarali H, Ersoy O and Ozlu O: Does premedication with dexmedetomidine provide perioperative hemodynamic stability in hypertensive patients? BMC Anesthesiol 14: 113, 2014.

11. Tang C, Hu Y, Zhang Z, Wei Z, Wang H, Geng Q, Shi S, Wang S, Wang $J$ and Chai X: Dexmedetomidine with sufentanil in intravenous patient-controlled analgesia for relief from postoperative pain, inflammation, and delirium after esophageal cancer surgery. Biosci Rep 40: BSR20193410, 2020.

12. Kang MH, Lee HJ, Lim YJ, Jeon YT, Hwang JW and Park HP: Preoperative dexmedetomidine attenuates hemodynamic responses to hydrodissection in patients undergoing robotic thyroidectomy. J Anesth 29: 191-197, 2015.

13. Kang R, Jeong JS, Ko JS, Lee SY, Lee JH, Choi SJ, Cha S and Lee JJ: Intraoperative dexmedetomidine attenuates norepinephrine levels in patients undergoing transsphenoidal surgery: A randomized, placebo-controlled trial. BMC Anesthesiol 20: 100, 2020.

14. Poonai N, Spohn J, Vandermeer B, Ali S, Bhatt M, Hendrikx S, Trottier ED, Sabhaney V, Shah A, Joubert G and Hartling L: Intranasal dexmedetomidine for procedural distress in children: A systematic review. Pediatrics 145: e20191623, 2020.

15. Yang F, Liu Y, Yu Q, Li S, Zhang J, Sun M, Liu L, Lei Y, Tian Q, Liu $\mathrm{H}$ and Tu S: The role of parents in reporting sedation outcomes in our analysis of 17948 pediatric patients undergoing procedural sedation with a combination of intranasal dexmedetomidine and ketamine. Paediatr Anaesth 29: $1208,2019$.
16. Cheung CW, Ng KF, Liu J, Yuen MY, Ho MH and Irwin MG: Analgesic and sedative effects of intranasal dexmedetomidine in third molar surgery under local anaesthesia. Br J Anaesth 107: 430-437, 2011.

17. Nooh N, Sheta SA, Abdullah WA and Abdelhalim AA: Intranasal atomized dexmedetomidine for sedation during third molar extraction. Int J Oral Maxillofac Surg 42: 857-862, 2013.

18. Svrakic M, Pollack A, Huncke TK and Roland JT Jr: Conscious sedation and local anesthesia for patients undergoing neurotologic and complex otologic procedures. Otol Neurotol 35: e277-e285, 2014.

19. Liu S, Wang Y, Zhu Y, Yu T and Zhao H: Safety and sedative effect of intranasal dexmedetomidine in mandibular third molar surgery: A systematic review and meta-analysis. Drug Des Devel Ther 13: 1301-1310, 2019.

20. Mondardini MC, Amigoni A, Cortellazzi P, Di Palma A, Navarra C, Picardo SG, Puzzutiello R, Rinaldi L, Vitale F, Marinosci GZ and Conti G: Intranasal dexmedetomidine in pediatrics: Update of current knowledge. Minerva Anestesiol 85: 1334-1345, 2019.

21. Messeha MM and El-Morsy GZ: Comparison of intranasal dexmedetomidine compared to midazolam as a premedication in pediatrics with congenital heart disease undergoing cardiac catheterization. Anesth Essays Res 12: 170-175, 2018.

22. Gupta A, Dalvi NP and Tendolkar BA: Comparison between intranasal dexmedetomidine and intranasal midazolam as premedication for brain magnetic resonance imaging in pediatric patients: A prospective randomized double blind trial. J Anaesthesiol Clin Pharmacol 33: 236-340, 2017.

23. Goyal S, Gupta KK and Mahajan V: A comparative evaluation of intravenous dexmedetomidine and fentanyl in breast cancer surgery: A prospective, randomized, and controlled trial. Anesth Essays Res 11: 611-616, 2017.

24. Nakanishi T, Yoshimura $\mathrm{M}$ and Toriumi T: Pectoral nerve II block, transversus thoracic muscle plane block, and dexmedetomidine for breast surgery in a patient with achondroplasia: A case report. JA Clin Rep 5: 47, 2019.

25. Mohamed SA, Fares KM, Mohamed AA and Alieldin NH: Dexmedetomidine as an adjunctive analgesic with bupivacaine in paravertebral analgesia for breast cancer surgery. Pain Physician 17: E589-E598, 2014.

26. Mak PH, Campbell RC and Irwin MG; American Society of Anesthesiologists: The ASA physical status classification: Inter-observer consistency. American society of anesthesiologists. Anaesth Intensive Care 30: 633-640, 2002.

27. Wikström L, Nilsson M, Broström A and Eriksson K: Patients' self-reported nausea: Validation of the numerical rating scale and of a daily summary of repeated numerical rating scale scores. J Clin Nurs 28: 959-968, 2019.

28. Iirola T, Vilo S, Manner T, Aantaa R, Lahtinen M, Scheinin M and Olkkola KT: Bioavailability of dexmedetomidine after intranasal administration. Eur J Clin Pharmacol 67: 825-831, 2011.

29. Yuen VM, Irwin MG, Hui TW, Yuen MK and Lee LH: A double-blind, crossover assessment of the sedative and analgesic effects of intranasal dexmedetomidine. Anesth Analg 105: 374-380, 2007.

30. Wang HM, Shi XY, Zhou JL and Xia YF: Comparison of dexmedetomidine and propofol for conscious sedation in inguinal hernia repair: A prospective, randomized, controlled trial. J Int Med Res 45: 533-539, 2017

31. Miller JW, Divanovic AA, Hossain MM, Mahmoud MA and Loepke AW: Dosing and efficacy of intranasal dexmedetomidine sedation for pediatric transthoracic echocardiography: A retrospective study. Can J Anaesth 63: 834-841, 2016.

32. Sheta SA, Al-Sarheed MA and Abdelhalim AA: Intranasal dexmedetomidine vs. midazolam for premedication in children undergoing complete dental rehabilitation: A double-blinded randomized controlled trial. Paediatr Anaesth 24: 181-189, 2014.

33. Plambech MZ and Afshari A: Dexmedetomidine in the pediatric population: A review. Minerva Anestesiol 81: 320-332, 2015.

34. Jia JE, Chen JY, Hu X and Li WX: A randomised study of intranasal dexmedetomidine and oral ketamine for premedication in children. Anaesthesia 68: 944-949, 2013.

35. Ryu DS, Lee DW, Choi SC and Oh IH: Sedation protocol using dexmedetomidine for third molar extraction. J Oral Maxillofac Surg 74: 926.e1-7, 2016.

36. Ebert TJ, Hall JE, Barney JA, Uhrich TD and Colinco MD: The effects of increasing plasma concentrations of dexmedetomidine in humans. Anesthesiology 93: 382-394, 2000. 
37. Zhang X, Bai X, Zhang Q, Wang X and Lu L: The safety and efficacy of intranasal dexmedetomidine during electrochemotherapy for facial vascular malformation: A double-blind, randomized clinical trial. J Oral Maxillofac Surg 71: 1835-1842, 2013.

38. Mohta M, Kalra B, Sethi AK and Kaur N: Efficacy of dexmedetomidine as an adjuvant in paravertebral block in breast cancer surgery. J Anesth 30: 252-260, 2016.

39. Su F and Hammer GB: Dexmedetomidine: Pediatric pharmacology, clinical uses and safety. Expert Opin Drug Saf 10: 55-66, 2011 .

40. Scholz J and Tonner PH: Alpha2-adrenoceptor agonists in anaesthesia: A new paradigm. Curr Opin Anaesthesiol 13: 437-442, 2000
41. Piao G and Wu J: Systematic assessment of dexmedetomidine as an anesthetic agent: A meta-analysis of randomized controlled trials. Arch Med Sci 10: 19-24, 2014.

42. Das R, Das RK, Sahoo S and Nanda S: Role of dexmedetomidine as an anaesthetic adjuvant in breast cancer surgery as a day-care procedure: A randomised controlled study. Indian J Anaesth 62: 182-187, 2018.

This work is licensed under a Creative Commons Attribution-NonCommercial-NoDerivatives 4.0 International (CC BY-NC-ND 4.0) License. 